University of Wisconsin Milwaukee

UWM Digital Commons

Geosciences Faculty Articles

Geosciences

6-14-2003

\title{
Source of tiny wiggles in Chron C5: A comparison of sedimentary relative intensity and marine magnetic anomalies
}

Julie A. Bowles

University of Wisconsin-Milwaukee, bowlesj@uwm.edu

Lisa Tauxe

University of California - San Diego

Jeffrey S. Gee

University of California - San Diego, jsgee@ucsd.edu

David McMillan

University of California - San Diego

Steve Cande

University of California - San Diego

Follow this and additional works at: https://dc.uwm.edu/geosci_facart

Part of the Earth Sciences Commons

\section{Recommended Citation}

Bowles, Julie A.; Tauxe, Lisa; Gee, Jeffrey S.; McMillan, David; and Cande, Steve, "Source of tiny wiggles in Chron C5: A comparison of sedimentary relative intensity and marine magnetic anomalies" (2003). Geosciences Faculty Articles. 7.

https://dc.uwm.edu/geosci_facart/7

This Article is brought to you for free and open access by UWM Digital Commons. It has been accepted for inclusion in Geosciences Faculty Articles by an authorized administrator of UWM Digital Commons. For more information, please contact open-access@uwm.edu. 


\title{
Source of tiny wiggles in Chron C5: A comparison of sedimentary relative intensity and marine magnetic anomalies
}

\author{
Julie Bowles, Lisa Tauxe, Jeff Gee, David McMillan, and Steve Cande \\ Scripps Institution of Oceanography, University of California San Diego, 9500 Gilman Drive, MC 0208, La Jolla, \\ California 92093,USA (jbowles@ucsd.edu; ltauxe@ucsd.edu; jsgee@ucsd.edu; dmcmillan@ucsd.eud; scande@ucsd.edu)
}

[1] In addition to the well-established pattern of polarity reversals, short-wavelength fluctuations are often present in both sea-surface data ("tiny wiggles") and near-bottom anomaly data. While a high degree of correlation between different geographical regions suggests a geomagnetic origin for some of these wiggles, anomaly data alone cannot uniquely determine whether they represent short reversals or paleointensity variations. Independent evidence from another geomagnetic recording medium such as deep-sea sediments is required to determine the true nature of the tiny wiggles. We present such independent evidence in the form of sedimentary relative paleointensity from Chron C5. We make the first comparison between a sedimentary relative paleointensity record (ODP Site 887 at $54^{\circ} \mathrm{N}, 148^{\circ} \mathrm{W}$ ) and deep-tow marine magnetic anomaly data $\left(43^{\circ} \mathrm{N}, 131^{\circ} \mathrm{W}\right)$ [Bowers et al., 2001] for Chron C5. The sediment cores are densely sampled at $\sim 2.5 \mathrm{kyr}$ resolution. The inclination record shows no evidence for reverse intervals within the $\sim 1$ myr-long normal Chron C5n.2n. Rock magnetic measurements suggest that the primary magnetic carrier is pseudo-single domain magnetite. We choose a partial anhysteretic magnetization (pARM) as our preferred normalizer, and the resulting relative paleointensity record is used as input to a forward model of crustal magnetization. We then compare the results of this model with the stacked deep-tow anomaly records. The two records show a significant degree of correlation, suggesting that the tiny wiggles in the marine magnetic anomalies are likely produced by paleointensity variations. An analysis of our sampling density suggests that if any reverse intervals exist at this site, they are likely to be $<5 \mathrm{kyr}$ in duration. Furthermore, we suggest that reverse intervals during Chron C $5 \mathrm{n} .2 \mathrm{n}$ documented in other locations are unlikely to be global.

Components: 8278 words, 17 figures, 1 table.

Keywords: Miocene relative paleointensity; tiny wiggles; marine magnetic anomalies.

Index Terms: 1521 Geomagnetism and Paleomagnetism: Paleointensity; 1517 Geomagnetism and Paleomagnetism: Magnetic anomaly modeling; 1535 Geomagnetism and Paleomagnetism: Reversals (process, timescale, magnetostratigraphy).

Received 5 December 2002; Revised 14 March 2003; Accepted 16 March 2003; Published 14 June 2003.

Bowles, J., L. Tauxe, J. Gee, D. McMillan, and S. Cande, Source of tiny wiggles in Chron C5: A comparison of sedimentary relative intensity and marine magnetic anomalies, Geochem. Geophys. Geosyst., 4(6), 1049, doi:10.1029/2002GC000489, 2003.

\section{Introduction}

[2] Sea surface magnetic anomaly profiles serve as the principal record of geomagnetic polarity rever- sals for the Cenozoic and much of the Mesozoic [Cande and Kent, 1995; Gradstein et al., 1994]. In addition to this globally recognized reversal sequence, shorter-wavelength anomaly variations 
within intervals of presumed constant polarity are also common. Variations in the thickness of the source layer or differences in magnetization related to alteration or geochemistry are undoubtedly responsible for some short-wavelength anomalies. Other short-wavelength variations, however, can be correlated among ocean basins and are generally recognized as a reflection of temporal changes in the dipole field [e.g., Blakely, 1974; Cande and LaBrecque, 1974]. The precise nature of these global, short-wavelength anomalies, termed "tiny wiggles" by LaBrecque et al. [1977], has remained in dispute, as they can be equally well modeled by either short field reversals or by paleointensity variations alone. A few tiny wiggles are now recognized as true short polarity intervals, such as the Cobb Mountain event at $\sim 1.2 \mathrm{Ma}$ [Mankinen et al., 1978; Mankinen and Gromme, 1982] and the Réunion event at $\sim 2.1 \mathrm{Ma}$ [Chamalaun and McDougall, 1966; McDougall and Watkins, 1973]. However, the source of most tiny wiggles remains ambiguous. Cande and Kent [1992] refer to these tiny wiggles as "cryptochrons" to reflect their uncertain origin as either short polarity reversals or intensity fluctuations. In particular, Blakely [1974] identifies three tiny wiggles within the long normal polarity interval of Chron C5n.2n during the late Miocene.

[3] The short-wavelength fluctuations within anomaly 5 can be easily seen in surface anomalies at fast- and intermediate-spreading ridges, and correlate well globally [Blakely, 1974; Cande and LaBrecque, 1974]. Bowers et al. [2001] examined both sea-surface and near-bottom profiles of the Chron C5 anomalies in the North Pacific on the west flank of the Gorda Ridge and in the South Pacific on the fast spreading East Pacific Rise at $19^{\circ} \mathrm{S}$. The Chron C5 tiny wiggles are easily identified in the surface profiles. The near-bottom profiles exhibit many short-wavelength anomalies that also correlate well between multiple lines in the same region, as well as between the North and South Pacific. On the basis of the character of these observed sea surface and deep tow anomalies, Bowers et al. [2001] suggest that most represent intensity fluctuations.

[4] The source of the Chron C5 tiny wiggles cannot be uniquely determined from marine magnetic anomalies, however, and confirmation from an independent recording medium is required. Volcanic sequences from both eastern [Watkins and Walker, 1977] and northwestern [McDougall et al., 1984] Iceland show evidence for a single reverse polarity interval within Chron C5n.2n. Exposed volcanic sequences covering this time period are rare, and sedimentary records are a reasonable choice of medium, because continuous records of both direction and relative intensity can be recovered. To identify short polarity intervals, a high sedimentation rate combined with a long, continuous, undisturbed section is generally desirable.

[5] Many studies have examined the Chron C5 interval in terrestrial sediment records, with varying results. Tauxe and Opdyke [1982] identify one short reverse period in the Bora Kas section of the Siwaliks in Pakistan. Rösler and Appel [1998] also document one short reverse period after dense resampling of parts of the Surai Khola section in the Nepalese Siwaliks. This reverse interval appears to correlate with that of Tauxe and Opdyke [1982] $\sim 1000 \mathrm{~km}$ to the west. Garcés et al. [1996] identify three short reversals in the Vallès-Penedès Basin of northeastern Spain, but the section containing these is characterized by a very large amount of scatter in the reported VGPs. Roperch et al. [1999] found one possible short reversal in the red bed sequence of the Corque basin in Bolivia, where the Chron C5 identification is nicely constrained by two welldated ash layers. Li et al. [1997] identify three possible short reversals within Chron C5n.2n in the terrestrial sediments of Longzhon Basin in western China, with a single sample locating each reversal. In all of these sedimentary studies - with the exception of Li et al. [1997] who report no estimate of scatter-the reported values for the Fisher precision statistic, k [Fisher, 1953], show significantly higher scatter than is expected to result from secular variation [McFadden et al., 1991]. This raises the possibility that at least some of the directional scatter (including reverse intervals) may be non-geomagnetic in origin, e.g., resulting instead from sediment disturbances.

[6] While terrestrial sediments often have high accumulation rates, they typically suffer from discontinuous sedimentation or poor exposure, making 


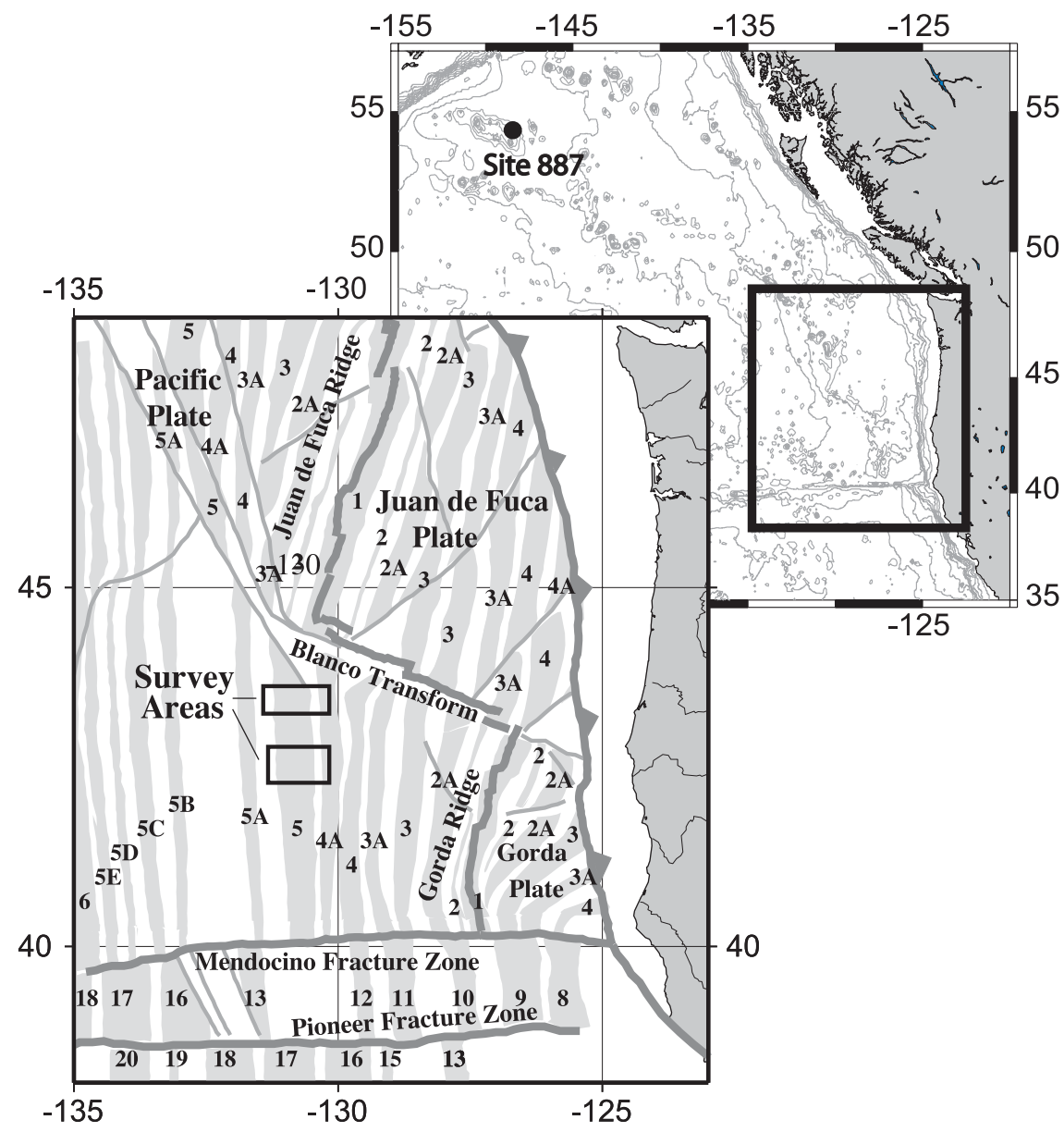

Figure 1. Map of study areas. Upper map shows location of ODP Site 887. Enlarged lower map shows locations of deep-tow magnetometer surveys.

it necessary to piece together sequences from different outcrops. This piecemeal construction can leave gaps or uncertainties about how the records fit together. As an alternative, marine sediments can in principle provide a long, continuous record of variations in the geomagnetic field. Of the 11 studies of marine sediments covering Chron C 5n.2n, only three have identified reverse intervals. Bleil [1989] finds several intervals in sediments from the Norwegian Sea, although most are recorded by a single sample only, and the sample spacing is very coarse $\left(30-70 \mathrm{~cm}\right.$, or $<10^{4}-10^{5}$ yrs). Tauxe et al. [1984] document a single interval (also constrained by a single sample) in South Atlantic sediments, with a sedimentation rate of $\sim 1 \mathrm{~cm} / \mathrm{kyr}$ and sample spacing of $10-40 \mathrm{~cm}$. North Pacific deep-sea sediments with a much higher sedimentation rate $(2-3 \mathrm{~cm} / \mathrm{kyr})$ and average sample spacing of roughly $26 \mathrm{~cm}$ revealed two reverse intervals [Roberts and Lewin-Harris, 2000]. However, the slightly to moderately deformed state of the cores [Rea et al., 1993] and the somewhat ambiguous magnetostratigraphic interpretation around Chron C5 leave room for other interpretations.

[7] Thus, of the 20 sedimentary magnetostratigraphic studies of Chron C5 (see Opdyke and Channell [1996] for review), only eight show reverse intervals. Of these, none demonstrate that the directional scatter observed is likely to be entirely of geomagnetic origin.

[8] In this paper we examine North Pacific sediments from Ocean Drilling Program Site 887, located at $54^{\circ} 22^{\prime} \mathrm{N}, 148^{\circ} 27^{\prime} \mathrm{W}$ on the Patton-Murray Seamount platform on the Pacific Plate (Figure 1), to evaluate the geomagnetic signal within Chron C5. We chose this site because of its excellent magnetostratigraphy [Weeks et al., 1995], allowing 


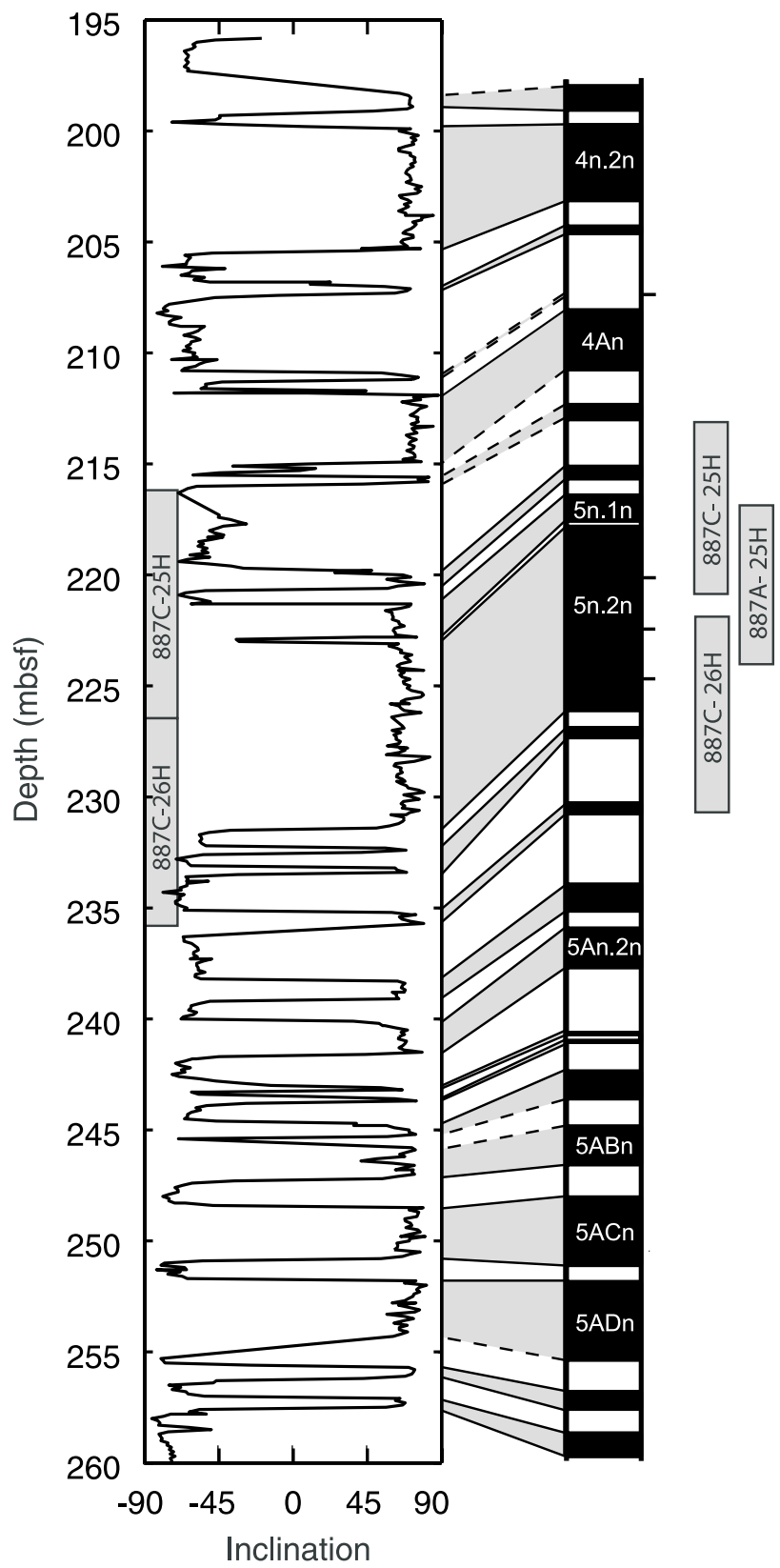

Figure 2. (left) Shipboard inclination data from Site 887, Hole C. The data shown are demagnetized to $15 \mathrm{mT}$, except where occasional core sections were not demagnetized. In these cases NRM data is used. The first $0.5 \mathrm{~m}$ of each core has been removed in case of possible coring disturbance. (right) Geomagnetic polarity timescale of Cande and Kent [1995]. Ticks to the right of the timescale indicate proposed cryptochrons. Note that depth scale is based on the assumption of continuous recovery. Further study indicates some missing section between cores $887 \mathrm{C}-25 \mathrm{H}$ and $887 \mathrm{C}-26 \mathrm{H}$. This is illustrated to the right of the timescale where the cores (including $887 \mathrm{~A}-25 \mathrm{H}$ ) are schematically placed within time.

us to unambiguously identify Chron C5 (Figure 2), and because of the site's relative proximity to the deep-tow magnetic survey of Chron C5 [Bowers et al., 2001] at $\sim 43^{\circ} \mathrm{N}$ (Figure 1). By comparing directions and relative paleointensity data from a densely sampled magnetostratigraphic record with the high-resolution, near-bottom anomalies, we address the question of whether the tiny wiggles in Chron C5 result from reversals or paleointensity variations. 
[9] We compensate for a relatively slow sedimentation rate of $\sim 1 \mathrm{~cm} / \mathrm{kyr}$ during Chron $\mathrm{C} 5 \mathrm{n} .2 \mathrm{n}$ with small sample size and dense sampling. We isolate characteristic remanent (ChRM) directions, as well as estimate relative paleointensity for all samples. We show that ChRM directions provide no evidence for reversals during Chron C5n.2n, but numerous fluctuations in relative paleointensity are evident. To determine if these fluctuations could account for the tiny wiggles in Chron C5, we produce a forward model of marine magnetic anomalies using the relative paleointensity as crustal magnetization input. We then compare the modeled anomaly to the observed deep-tow stack from the North Pacific and discuss the factors-including sedimentation rate changes - which might affect the coherence between the two records. Finally, we discuss the temporal resolution of our sediment samples and the possible origin of the tiny wiggles.

\section{Methods}

[10] On the basis of the shipboard magnetostratigraphic record of Hole 887C (Figure 2) [Weeks et al., 1995], the two cores spanning Chron C5n.2n (cores $887 \mathrm{C}-25 \mathrm{H}$ and $887 \mathrm{C}-26 \mathrm{H}$ ) were selected for discrete sampling. We also sampled core $887 \mathrm{~A}-25 \mathrm{H}$ from the adjacent hole, which spans the gap between $887 \mathrm{C}-25 \mathrm{H}$ and $887 \mathrm{C}-26 \mathrm{H}$ (Figure 2). The sampled sediments are predominantly gray to brown clayey diatom oozes. Three ash layers and several horizons with burrows containing volcanic glass were present in the cores [Rea et al., 1993]. The top $10 \mathrm{~cm}$ and bottom $97 \mathrm{~cm}$ of $887 \mathrm{~A}-25 \mathrm{H}$, and the top $\sim 17 \mathrm{~cm}$ of 887C-26H were disturbed [Rea et al., 1993].

[11] Partially oriented samples were taken with glass tubes $1 \mathrm{~cm}$ in diameter and $3.5 \mathrm{~cm}$ in length. Samples were taken approximately every $2.5 \mathrm{~cm}$ downcore, which at an average sedimentation rate of $\sim 1 \mathrm{~cm} / \mathrm{kyr}$ during Chron C5n.2n corresponds to a maximum temporal resolution of about $2.5 \mathrm{kyr}$. One exception is over the interval 223.06-224.34 mbsf in core $887 \mathrm{C}-25 \mathrm{H}$ where the core had dried out, making sampling with the relatively fragile glass tubes impossible. Instead, samples over this interval were taken every $5-10 \mathrm{~cm}$ with $8 \mathrm{~cm}^{3}$ plastic cubes.
[12] To establish the suitability of these sediments for paleointensity analysis, we test each of the attributes summarized by King et al. [1983] and Tauxe [1993] as desirable for inclusion in relative paleointensity studies. Among these are the requirements that (1) the characteristic remanence be a single, well-defined component of magnetization; (2) the natural remanence (NRM) be carried by magnetite, in a size range able to carry a stable characteristic direction; (3) bulk magnetic properties should be uniform with respect to some concentration normalizing parameter; and (4) the concentration of magnetic grains, measured here as variation in anhysteretic remanent magnetization (ARM) or isothermal remanent magnetization (IRM), should not vary by more than a factor of 30 .

[13] Pilot samples were either thermally demagnetized in $50^{\circ} \mathrm{C}$ steps or AF demagnetized in steps up to $100 \mathrm{mT}$. Results of these pilot samples (Figure 3) showed that in most cases a characteristic remanence (ChRM) was isolated by $15 \mathrm{mT}$, and in all cases by $30 \mathrm{mT}$. We therefore AF demagnetized the remainder of the samples at 15 and $30 \mathrm{mT}$. All samples were given a saturation IRM (SIRM) at 2.5 $\mathrm{T}$, followed by a $0.3 \mathrm{~T}$ IRM in the opposite direction. This allows the calculation of the $\mathrm{S}$ ratio of the low-coercivity component to the SIRM according to the formula of Thompson and Oldfield [1986], $\mathrm{S}=-\mathrm{IRM}_{0.3} / \mathrm{SIRM}$. An additional 12 samples were subjected to the Lowrie 3-axis IRM experiment [Lowrie, 1990], where IRMs of 2.5, 0.3, and $0.1 \mathrm{~T}$ are applied in three orthogonal directions to separate the high-, intermediate-, and low-coercivity spectra. The samples were then thermally demagnetized to provide information on the blocking temperature spectra of the various coercivity fractions. Hysteresis loops were measured on 12 samples using a Micromag alternating gradient force magnetometer. Bulk susceptibility was also measured on all samples.

[14] While we originally intended to normalize the NRM data by IRM, reviewer comments prompted us to reconsider using ARM. Because the samples had already been given a SIRM that could not be completely AF demagnetized, we measured the ARM in two steps. First, we AF demagnetized the samples at $120 \mathrm{mT}$ and measured the remaining 


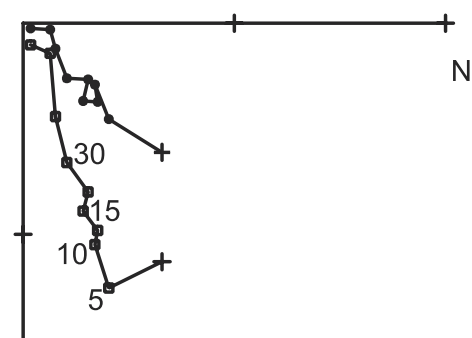

$\mathrm{N}$

Hole $887 \mathrm{C}, 226.300 \mathrm{mbsf}$

$\mathrm{E}, \mathrm{V}$

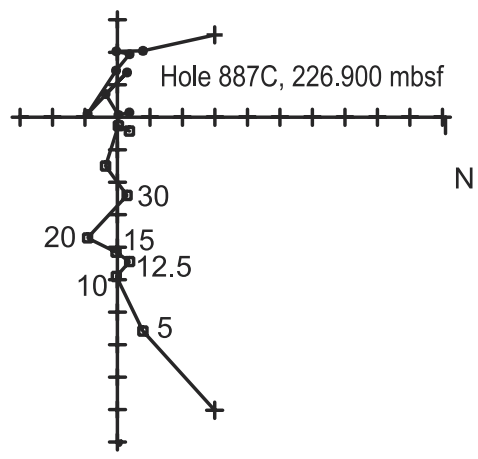

$E, V$

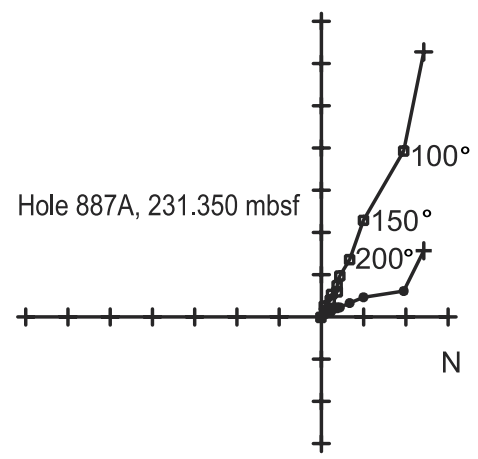

$E, V$

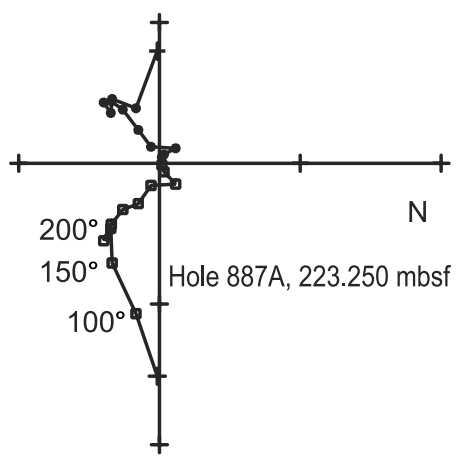

E,V

Figure 3. Typical results of AF (left) and thermal (right) demagnetization. Horizontal projection plotted in filled circles, vertical projection in open squares. Many samples show a low-stability overprint that is usually removed by $30 \mathrm{mT}$ or $200^{\circ} \mathrm{C}$.

high-coercivity component. We then gave the samples a partial ARM (pARM) from 100 to $30 \mathrm{mT}$ with a $50 \mu \mathrm{T}$ bias field and remeasured the samples. The magnitude of the $\mathrm{pARM}_{30-100}$ was found by computing the vector difference between first and second measurements. This pARM $_{30-100}$ was designed to activate the same coercivity spectrum as seen in our NRM data, demagnetized to $30 \mathrm{mT}$.

[15] Because we estimate paleointensity on all samples by NRM demagnetized to $30 \mathrm{mT}$, it is also important to ensure that any viscous remanence (VRM) has been completely removed by 30 $\mathrm{mT}$. To check this, we carried out "pseudo-Thellier" experiments [Tauxe et al., 1995] on 20 samples. This technique is similar to the method of Thellier and Thellier [1959], but modified for acquisition of pARMs rather than pTRMs (partial thermoremanent magnetization). The sample is AF demagnetized in steps, and then given an ARM in the same steps with a $50 \mu \mathrm{T}$ bias field. The absolute value of the slope of the data, when plotted as NRM remaining versus pARM gained, provides an estimate of relative paleointensity, as well as shows the demagnetization step that removes all VRM.

\section{Results}

\subsection{Directional Data}

[16] Both AF and thermal demagnetization on selected samples distributed throughout the cores show the removal of a soft, low-temperature overprint by $30 \mathrm{mT}$ and $200^{\circ} \mathrm{C}$ (Figure 3). After removal of this overprint, a single component of magnetization is generally isolated. The ChRM isolated in all samples by AF demagnetization to $30 \mathrm{mT}$ is shown in Figure 4. Because the cores are 

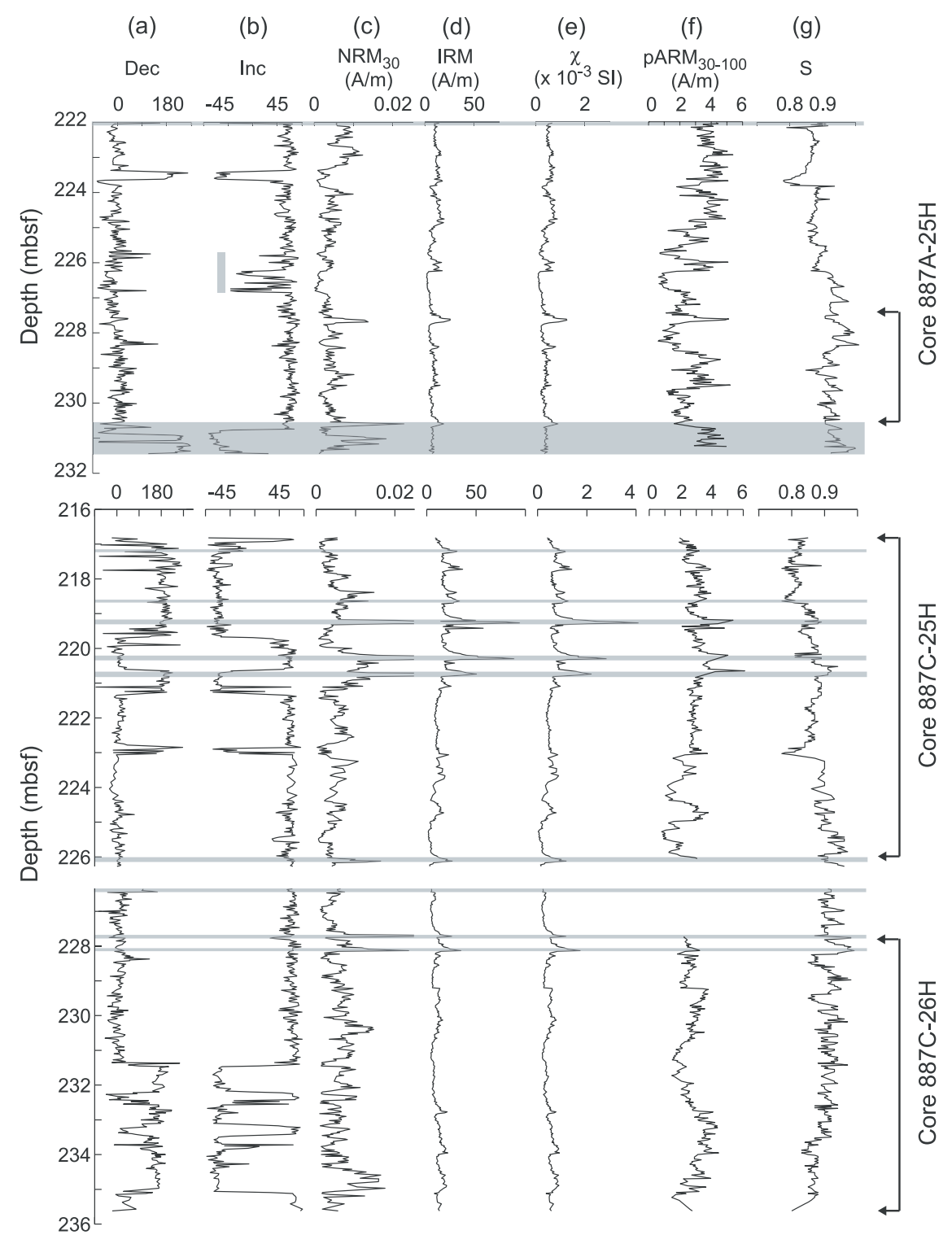

Figure 4. Data from all discrete samples. Horizons highlighted in gray correspond to disturbed levels or levels with ash or glass which were not used in the final analysis. Arrows to right indicate portion of data used in final composite record (see text). (a) Declination, (b) inclination, and (c) intensity after demagnetization to $30 \mathrm{mT}$. Mean normal declination for each core assigned a value of zero. Vertical gray bar indicates region of anomalous inclinations (see text). Some of the intensity data exceeds the scale shown and has been truncated at $0.025 \mathrm{~A} / \mathrm{m}$. (d) Saturation IRM. (e) Volume-normalized susceptibility. (f) Partial ARM from 30 to $100 \mathrm{mT}$. (g) S ratio of low-coercivity component (at $0.3 \mathrm{~T})$ to saturation IRM $(2.5 \mathrm{~T})$.

unoriented with respect to declination, the mean normal declination for each core has been adjusted to zero (Figure 4a). Samples corresponding to disturbed layers, ash layers, or layers with volcanic glass are highlighted in gray. After removing these highlighted layers, the ChRM directions for each core (Figure 5 and Table 1) have relatively high precision values (k), and exhibit VGP scatter (Table 1) consistent with expected values due to secular variation [McFadden et al., 1991]. The data from $887 \mathrm{C}-25 \mathrm{H}$ are essentially antipodal, while those from $887 \mathrm{C}-26 \mathrm{H}$ are not quite antipodal (Figure 5). Core 887A-25H does not have sufficient reverse data to make such a determination. 

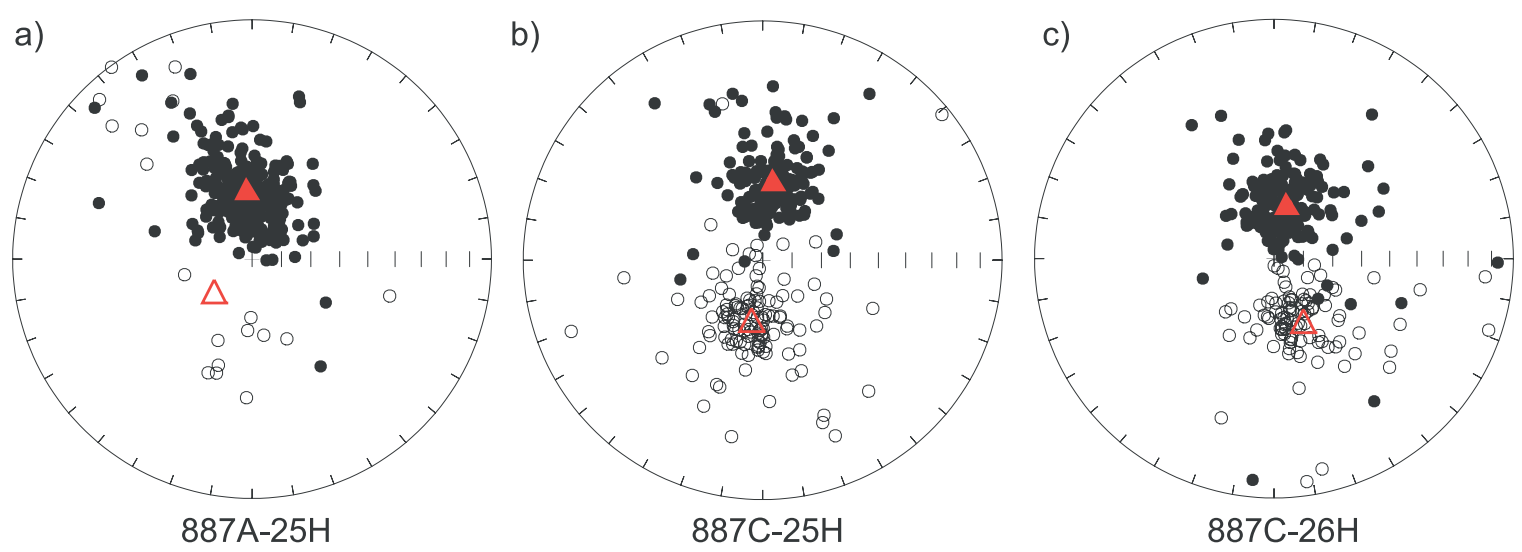

Figure 5. Directional data for all discrete samples after demagnetization to $30 \mathrm{mT}$. Filled (open) red triangles represent normal (reverse) means based on a non-parametric bootstrap analysis.

[17] Core $887 \mathrm{~A}-25 \mathrm{H}$ contains a section with anomalous inclinations from $\sim 225.75-226.80 \mathrm{mbsf}$, as indicated by the gray vertical bar in Figure 4b. In an effort to understand these anomalous inclinations, we measured anisotropy of magnetic susceptibility (AMS) for a selection of samples above, within, and below the affected interval. Results show that outside this interval, samples are characterized by oblate AMS fabrics, typical of primary sedimentary fabrics (Figures 6a and 6c). Within the interval, however, samples show a triaxial fabric, with distinct maximum and intermediate eigenvectors (Figure 6b). This may be indicative of postdepositional modification [Cronin et al., 2001], and no samples from this interval were used in the final analysis.

[18] The data are not Fisher distributed, but rather display a distribution with anomalous inclinations associated with low intensities (Figure 7). If we exclude those data with the lowest intensities ( $<25 \%$ of the maximum value), the remaining data from all cores show a Fisher distribution. A similar phenomenon of anomalous directions associated with low intensities has also been observed in absolute paleointensity data [e.g., Tanaka et al., 1995; Merrill et al., 1998].

\subsection{Rock Magnetics}

[19] Hysteresis loops suggest that the primary magnetic phase is pseudo-single domain in size. Thermal demagnetization of a three-component IRM (Lowrie 3-D test) (Figure 8) shows that the sediments are dominated by a magnetic phase with coercivities under $0.3 \mathrm{~T}$, and with unblocking temperatures below $600^{\circ} \mathrm{C}$. Also present, however, is a small fraction (average of 7\%) of highcoercivity material that is not completely unblocked even at $600^{\circ} \mathrm{C}$. This is consistent with a magnetic mineralogy comprised primarily of magnetite, but with a small component of hematite. The $\mathrm{S}$ ratio, measured on all samples (Figure 4g), demonstrates that this low-coercivity (magnetite) fraction varies between 0.85 and 1.0 during the interval of primary interest, Chron C5n.2n.

[20] To investigate the uniformity of the sediment with respect to our possible normalizing parameters $\left(\mathrm{pARM}_{30-100}, \mathrm{SIRM}\right.$, and susceptibility), we

Table 1. Mean Core Directions and Dispersion ${ }^{\mathrm{a}}$

\begin{tabular}{lrrrccc}
\hline & $\mathrm{D}$ & $\mathrm{I}$ & $\mathrm{N}$ & $\mathrm{S}_{\lambda}$ & $\mathrm{S}_{\mathrm{L}}$ & $\mathrm{S}_{\mathrm{U}}$ \\
\hline 887A-25H-normal & 355.1 & 66.6 & 279 & 19.1 & 18.1 & 20.2 \\
887A-25H-reverse & 226.1 & -72.6 & 15 & & & \\
887C-25H-normal & 7.0 & 62.9 & 171 & 17.1 & 16.4 & 19.0 \\
887C-25H-reverse & 190.3 & -68.3 & 122 & & & \\
887C-26H-normal & 13.5 & 71.3 & 198 & 18.9 & 17.8 & 20.0 \\
887C-27H-reverse & 156.1 & -65.3 & 99 & & & \\
\hline
\end{tabular}

${ }^{\mathrm{a}} \mathrm{D}$, mean declination; I, mean inclination; $\mathrm{N}$, number of samples. Mean directions calculated with non-parametric bootstrap. $S_{\lambda}$, mean angular dispersion of VGPs; $\mathrm{S}_{\mathrm{L}}$ and $\mathrm{S}_{\mathrm{U}}$, lower and upper $95 \%$ confidence limits on $S_{\lambda} . S_{\lambda}, S_{L}$ and $S_{U}$ calculated using combined normal and reverse data from each core and with a VGP colatitude cutoff of 40, as in McFadden et al. [1991]. Values expected from paleosecular variation at the latitude of Site 887: $\mathrm{S}_{\lambda}=18.9, \mathrm{~S}_{\mathrm{L}}=17.6$, and $\mathrm{S}_{\mathrm{U}}=20.4$ [McFadden et al., 1991]. 

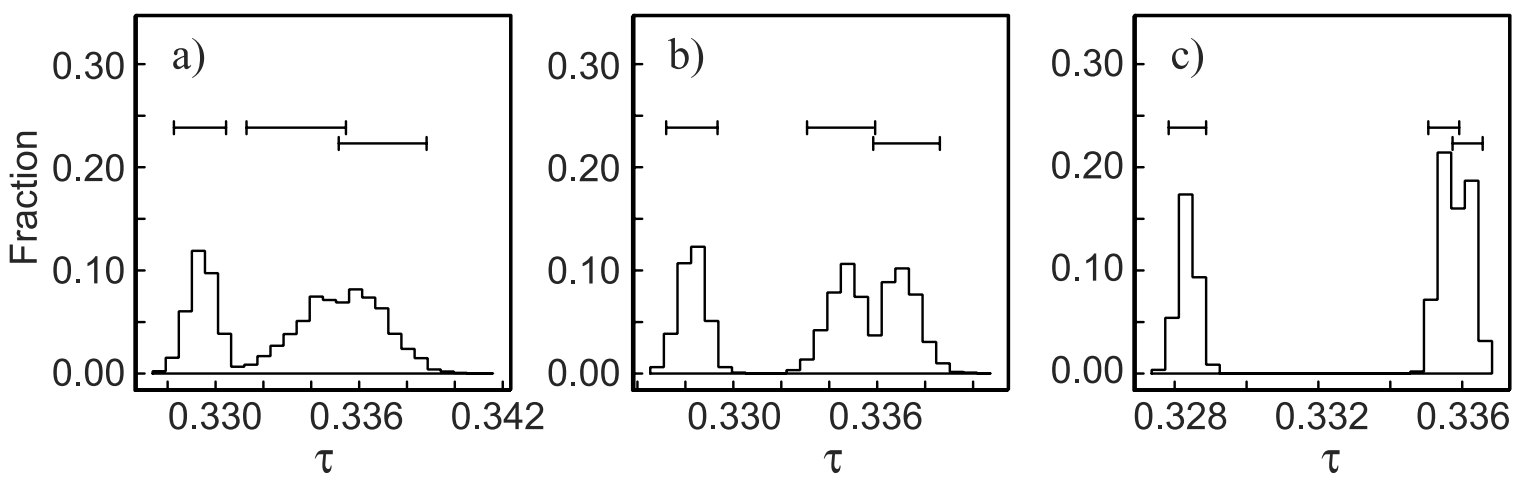

Figure 6. Histograms of bootstrapped AMS eigenvalues $(\tau)$ for selected samples from core $887 \mathrm{~A}-25 \mathrm{H}$. 95\% confidence bounds for each eigenvalue are shown as horizontal bars. Samples are from (a) above, (b) within, and (c) below the core interval affected by anomalous inclinations. Note that the sample groups from above and below (Figures 6a and 6c) are characterized by oblate AMS fabrics $\left(\tau_{\max }=\tau_{\text {int }}>\tau_{\min }\right)$ typical of primary sedimentary fabrics. The group from within the affected interval (Figure 6b) exhibits a triaxial fabric $\left(\tau_{\max }>\tau_{\text {int }}>\tau_{\text {min }}\right)$ which may be indicative of post-depositional modification [Cronin et al., 2001].

plot susceptibility $(\chi)$ versus $\mathrm{pARM}_{30-100}$ and versus SIRM (Figure 9). The excellent correlation between SIRM and $\chi$ suggests that either will make a suitable normalizer. While the correlation between pARM and $\chi$ is not as ideal, this likely reflects the fact that ARM is relatively insensitive to larger grain sizes, while both SIRM and $\chi$ will be dominated by large grains if present. Furthermore, the variation in either pARM or SIRM values, used as a proxy for concentration changes, suggests that the concentration of magnetic particles varies at most by a factor of $\sim 50$. However, the variation over Chron C $5 n .2 n$ is less than a factor of 30, as recommended by King et al. [1983] for uniform sediments.

[21] We have shown that the sediments have a single-component characteristic remanence carried primarily by stable magnetite. Further, we likely have uniformity of the sediment with respect to any of our proposed normalizers and with respect to concentration of magnetic particles. Results of the pseudo-Thellier experiments show removal of a viscous component by $30 \mathrm{mT}$ (Figure 10) which agrees with data from AF demagnetization (Figure 3). Most samples show a slight curvature from 5 to 15 or $30 \mathrm{mT}$, or a slope that is distinctly different from the higher steps. This indicates the presence of a viscous component in the normal direction [Kok and Tauxe, 1999], that is easily removed by cleaning to $30 \mathrm{mT}$.

\subsection{Inter-Hole Correlation}

[22] In comparing data from Holes 887A and $887 \mathrm{C}$, it is evident that there was incomplete recovery between cores $887 \mathrm{C}-25 \mathrm{H}$ and $887 \mathrm{C}-26 \mathrm{H}$ (Figure 11). To construct a continuous record of paleointensity variations, we therefore used nearly $3 \mathrm{~m}$ of core $887 \mathrm{~A}-25 \mathrm{H}$ to bridge the gap between $887 \mathrm{C}-25 \mathrm{H}$ and $887 \mathrm{C}-26 \mathrm{H}$. Arrows in Figure 4 show the portions of the cores used in the composite record. The good match between shipboard susceptibility, density, and gray scale (Figure 11)

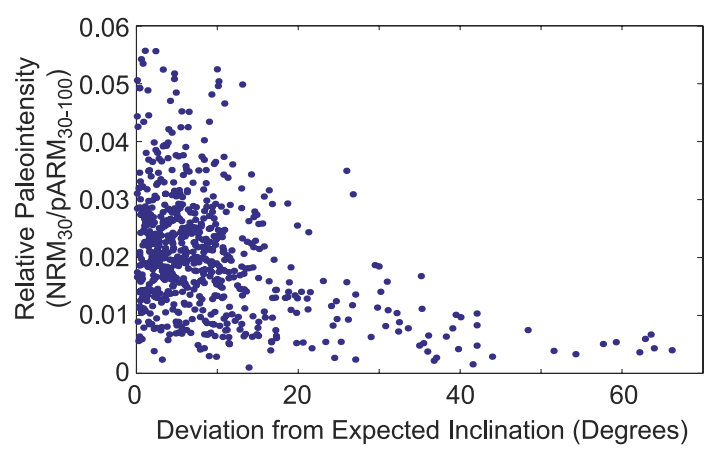

Figure 7. Paleointensity versus deviation from expected inclination for discrete samples taken from Holes 887A and 887C (excluding those associated with core disturbances or ash layers). Shown on the vertical axis is relative paleointensity, estimated as NRM demagnetized to $30 \mathrm{mT}$ and normalized by a partial ARM from 30$100 \mathrm{mT}$. The data show low paleointensities associated with anomalous directions, which appears to result overall in a non-Fisherian distribution of directions. 

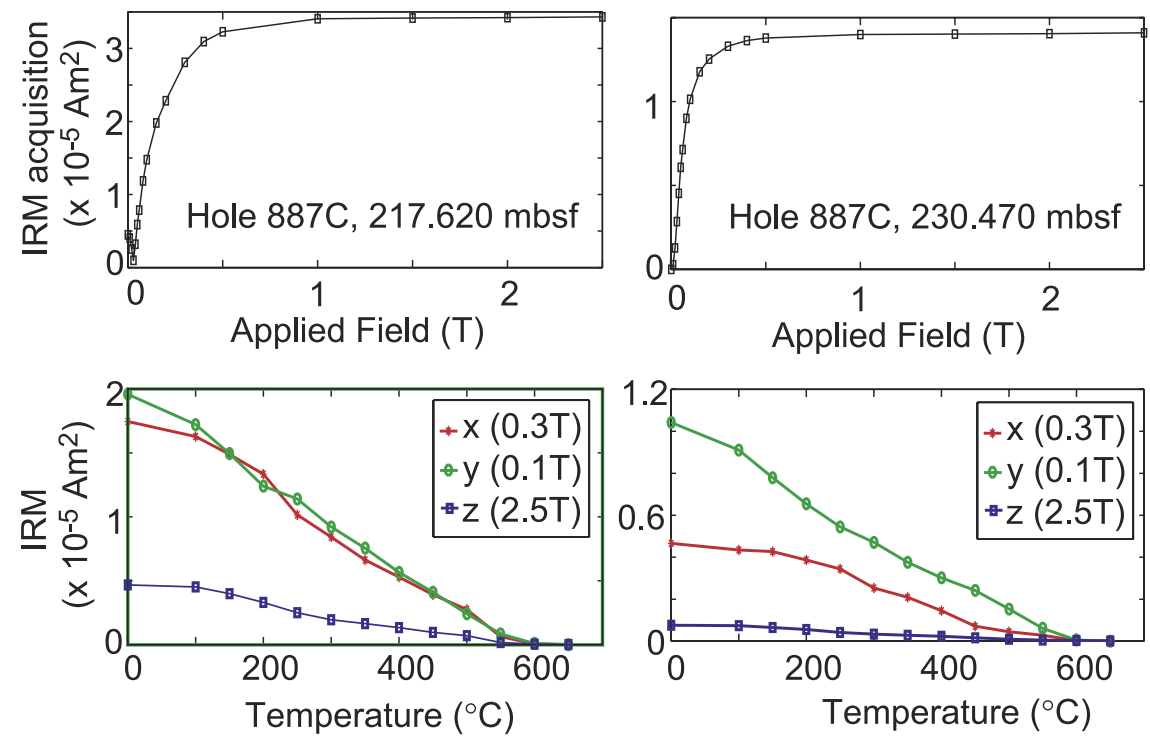

Figure 8. Typical results from IRM acquisition and Lowrie 3D IRM tests [Lowrie, 1990]. Results are consistent with the predominance of magnetite and a small component of hematite.

makes us confident we have spliced the records correctly.

[23] We construct a composite depth record, starting at the top of core $887 \mathrm{C}-25 \mathrm{H}$ at $216.8 \mathrm{mbsf}$. We remove all samples associated with core disturbances or ash layers. These intervals are indicated in Figure 4 by the shaded horizons. While the ash layers should be essentially instantaneous in time, we do not close up these intervals because some reworking of the sediments has resulted in a gradational upper boundary. Therefore removal of these horizons leaves small gaps of $4-20 \mathrm{~cm}$ in the sampled record. Ages are assigned to the resulting record based on known reversals and assuming constant sedimentation between these reversals. We include among known reversals the short reverse interval within Chron C5r.1n that is not presently included in the geomagnetic timescale, but which has frequently been observed in both deep-tow anomaly profiles as well as surface profiles at fast spreading ridges [Bowers et al., 2001], and in deep-sea sediments [Schneider, 1995].

\subsection{Relative Paleointensity}

[24] As demonstrated above, either $\mathrm{pARM}_{30-100}$, SIRM or $\chi$ are likely to make suitable normalizers for relative paleointensity. Figure 12 shows NRM demagnetized to $30 \mathrm{mT}\left(\mathrm{NRM}_{30}\right)$ normalized by a)

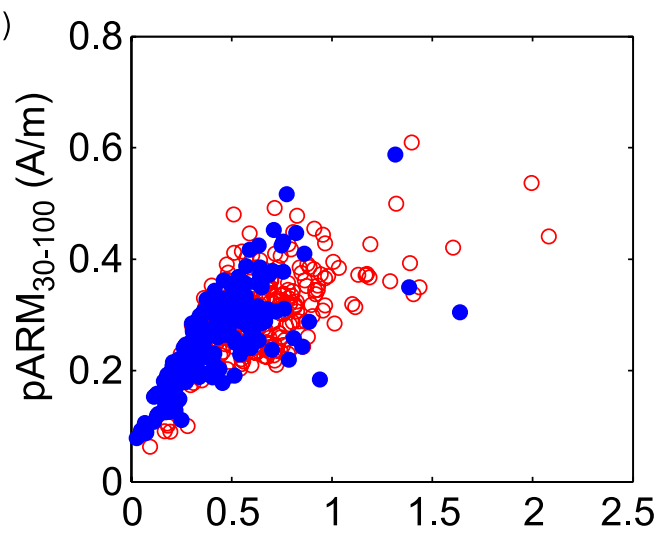

b)

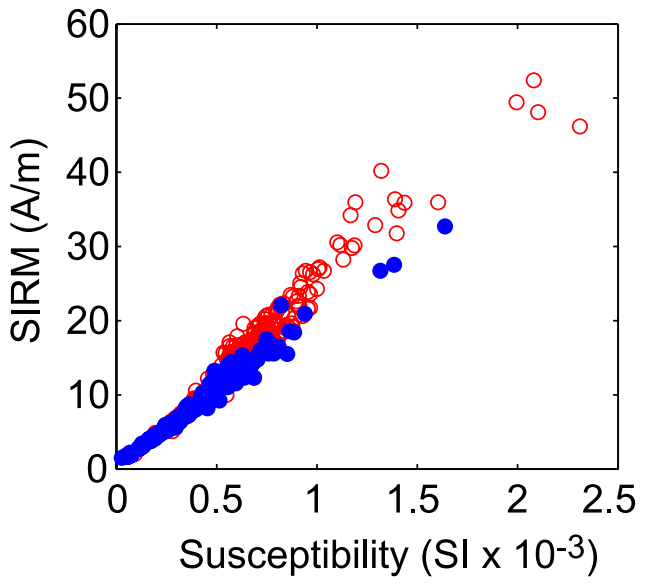

Figure 9. (a) Partial ARM and (b) saturation IRM plotted against susceptibility. Solid blue circles represent data from the long normal Chron C5n.2n. Open red circles show the remainder of the data. 

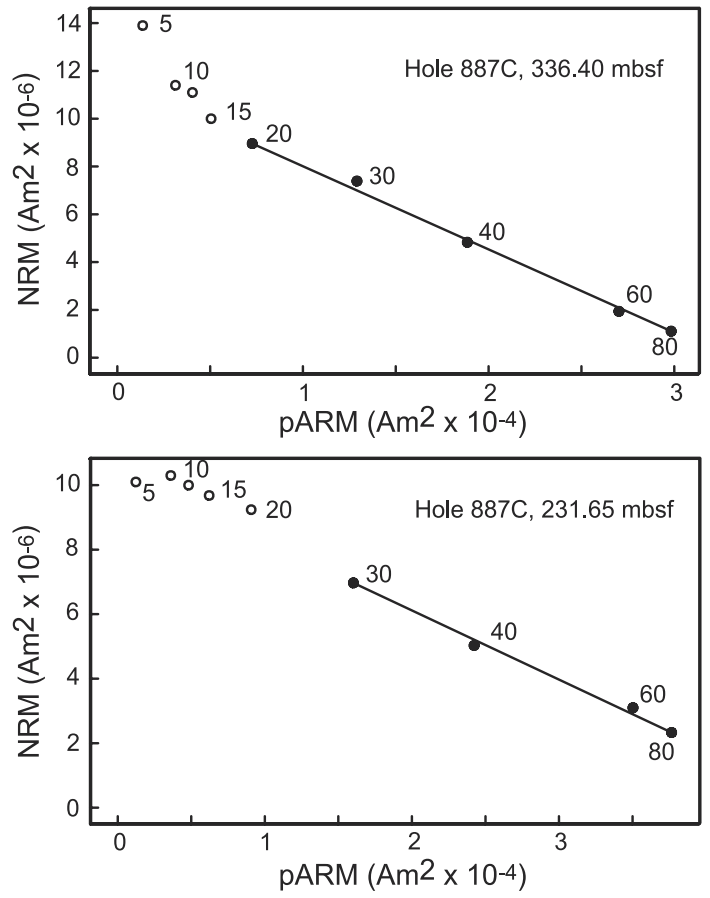

Figure 10. Representative results from pseudo-Thellier experiments. Removal of a viscous component is complete in all samples by $30 \mathrm{mT}$.

each of these variables and plotted against composite depth. In fact, the three records are very similar. To choose among them, we follow Constable et al. [1998] in determining which normalizer is most correlated with NRM. In this case, $\mathrm{pARM}_{30-100}$ is coherent with NRM over a slightly wider frequency band and shows a higher correlation coefficient with $\operatorname{NRM}(0.71$, versus 0.60 for SIRM and 0.64 for $\chi$ ).

[25] Finally, to evaluate any correlation between changes in magnetic mineralogy and paleointensity downcore, we calculate the coherence between the $\mathrm{S}$ ratio and relative paleointensity (Figure 13). Over the entire composite record (Figure 13a), there is a very small peak in the coherence at $\sim 0.005 \mathrm{kyr}-1$ ( $200 \mathrm{kyr})$. However, over the long normal C $5 \mathrm{n} .2 \mathrm{n}$, the records are not coherent at all at the 95\% confidence level (Figure 13b). This suggests that any changes in magnetic mineralogy are not affecting our relative paleointensity estimates.

\section{Discussion}

[26] The composite inclination record from Holes 887A and $887 \mathrm{C}$ (Figure 14a) shows no evidence for reversals in Chron C5n.2n. At a sample spacing of $\sim 2.5 \mathrm{~cm}$ and an average sedimentation rate of approximately $1 \mathrm{~cm} / \mathrm{kyr}$ during this interval, we would expect to resolve any reverse polarity intervals of at least $5 \mathrm{kyr}$ or longer. We very clearly resolve the reverse interval between $\mathrm{C} 5 \mathrm{n} .1 \mathrm{n}$ and C5n.2n (Figure 14a) which is $35 \mathrm{kyr}$ in duration and where the average sedimentation rate is significantly lower-about $0.5 \mathrm{~cm} / \mathrm{kyr}$.

[27] While we see no evidence for reversals within the long normal C5n.2n, there are significant variations in relative paleointensity down-core. Many reversals are associated with paleointensity lows (as would be expected), but similar lows throughout Chron 5 show no accompanying directional change. To see whether these paleointensity variations alone can account for the tiny wiggles in Anomaly 5, we make a forward model with the relative paleointensity (multiplied by the sign of the inclination) as magnetization input (Figure $14 \mathrm{~b}$ ). We assume a constant half-spreading rate of $42.8 \mathrm{~mm} / \mathrm{yr}$, to agree with the spreading rate calculated for Anomaly $5 \mathrm{n} .2 \mathrm{n}$ from the north Pacific deep-tow anomalies. The simple model, based on the FFT method of Parker and Heustis [1974], uses a Gaussian filter of $0.35 \mathrm{~km}(1 \sigma)$ to simulate the extrusion process [Schouten and McCamy, 1972]. The resulting modeled anomaly, evaluated at the pole and at $300 \mathrm{~m}$ above a flat basement, is compared to the observed stacked anomalies in Figure 14c. The North Pacific deeptow lines have been reduced to the pole and stacked as in Bowers et al. [2001]. There are effectively two tie points between the modeled and observed anomalies at the young and old ends of Anomaly 5n.2n.

\subsection{Correlation Between Records}

[28] Qualitatively, the location and amplitude of many of the tiny wiggles in Anomaly 5n.2n appear to be reproduced in the modeled anomaly quite well, especially in the younger half of Anomaly $5 \mathrm{n} .2 \mathrm{n}$ where the tiny wiggles in the deep-tow anomaly are reproduced nearly peak for peak in the modeled anomaly. The dip in $5 \mathrm{n} .1 \mathrm{n}$, as well as some of the small wiggles around $5 \mathrm{r} .1 \mathrm{n}$ are also duplicated by the model. We note that the older 

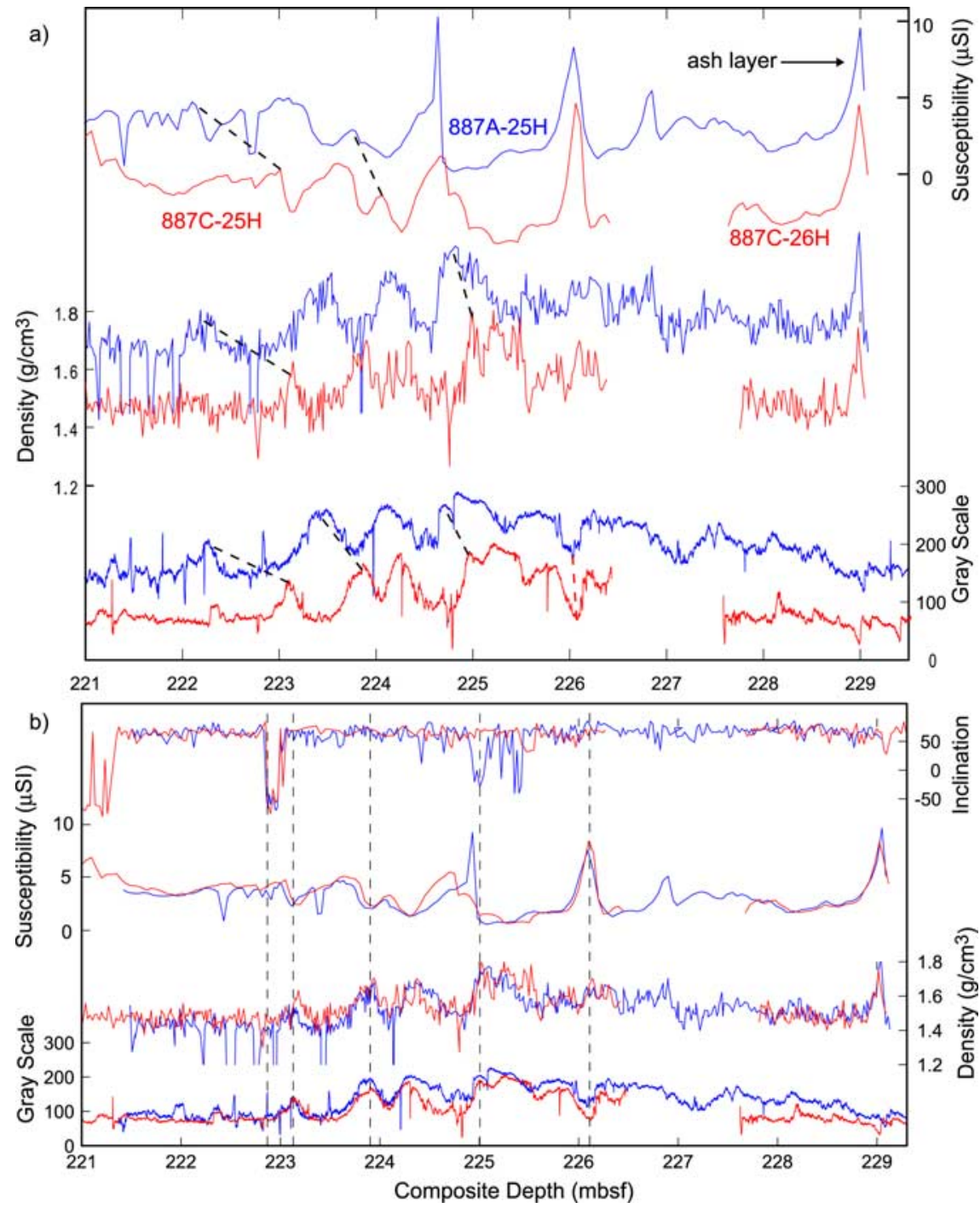

Figure 11. (a) Correlation between Holes 887A (blue) and 887C (red). "Composite depth" starts at the top of core $887 \mathrm{C}-25 \mathrm{H}$ at $216.8 \mathrm{mbsf}$. The gap in the Hole $887 \mathrm{C}$ records is that between cores $887 \mathrm{C}-25 \mathrm{H}$ and $887 \mathrm{C}-26 \mathrm{H}$. Susceptibility and density are shipboard data. Gray scale is taken from core photos scanned from Rea et al. [1993]. (b) Same as for Figure 11a, but with Hole 887A data compressed to compensate for presumed core expansion. Tie points for compression (dashed black lines) chosen based on gray scale and reversals only.

half of Anomaly $5 \mathrm{n} .2 \mathrm{n}$ is comprised of data primarily from core $887 \mathrm{C}-26 \mathrm{H}$, which is characterized by directions that are not quite antipodal. This may contribute to the disagreement between the two records over this interval.

[29] To quantify the agreement between the modeled and observed stacked anomalies, the two anomalies show statistically significant coherence ( $>95 \%$ confidence) over frequencies $<\sim 0.018$ $\mathrm{kyr}^{-1}$ ( $\sim 55 \mathrm{kyr}$ ) (Figure 15a). Because this high coherence results primarily from the presence of known reversals, we also show the coherence over Anomaly 5n.2n only (Figure 15b). The two records now show significant coherence only at frequencies $<\sim 0.01 \mathrm{kyr}^{-1}(\sim 100 \mathrm{kyr})$. However, if we add two tie points within C5n.2n (as shown in Figures $15 \mathrm{~b}$ and $15 \mathrm{c}$ ), assuming some offset between the records due to sediment accumulation or spreading rate variations, we see that coherence is significantly increased to frequencies $<\sim 0.022 \mathrm{kyr}^{-1}$ ( $\sim 45 \mathrm{kyr}$ ). This illustrates the extreme sensitivity of coherence to slight changes in the records being compared. 


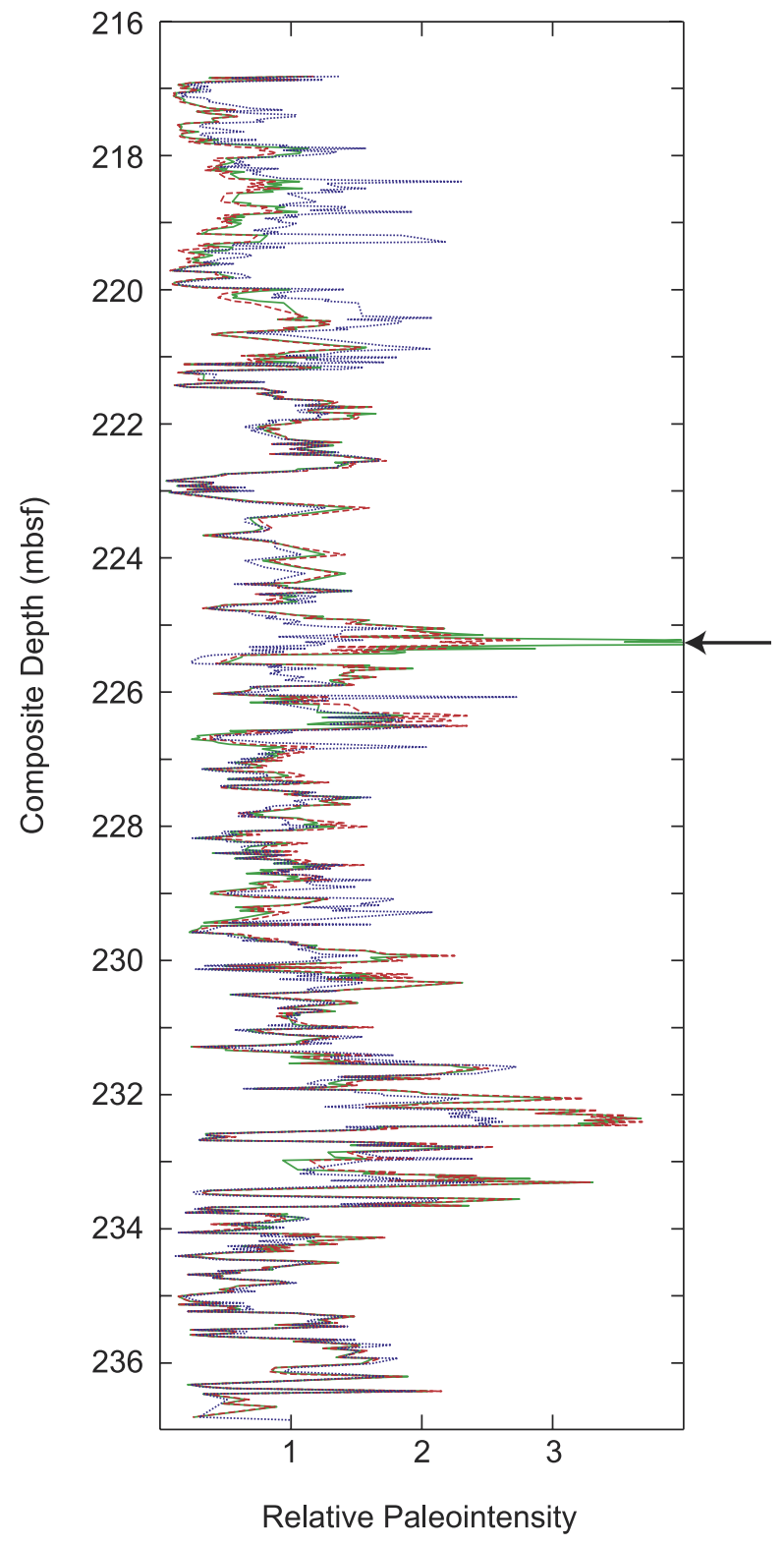

Figure 12. Relative paleointensity for the three possible normalizers, $\mathrm{pARM}_{30-100}$ (blue dotted line), SIRM (red dashed line), and susceptibility (solid green line). All are normalized to a mean of 1 . Note that the susceptibility-normalized data extend off-scale where indicated by the arrow.

[30] Before we conclude whether or not this level of coherence represents good agreement between the records, it is useful to consider all the factors that can serve to decrease coherence, even if both records have accurately recorded the field. Misidentification of tie points in the anomaly records during stacking can result in a complete loss of the high-frequency signal in the stack. This is demonstrated in Figure 16 where we have restacked 4 individual anomaly records, imposing random tie point errors with a standard deviation of 10 kyr. Coherence between this new stack and the original stack shows a loss of signal at periods $<20-28$ kyr.

[31] Unknown changes in the sediment accumulation rate (SAR) can also severely decrease coherence between the two records. To demonstrate how much reduction in coherence we might expect from SAR changes alone, we assume for the moment that our relative paleointensity record from Site 887 represents the "true" geomagnetic changes during Chron C5n.2n. We then assume that an ideal sedimentary column records the field perfectly, but with changes in the SAR. We impose

a)

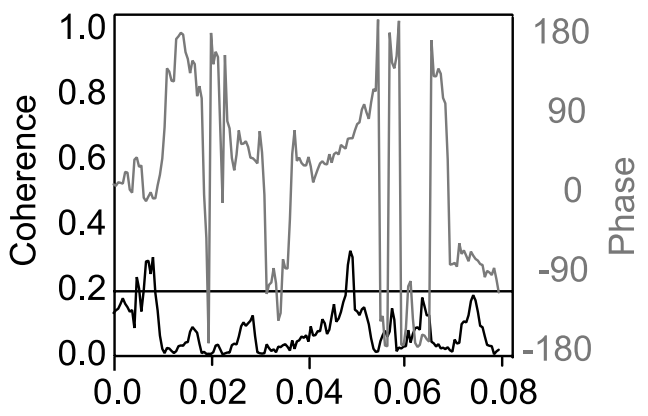

b)

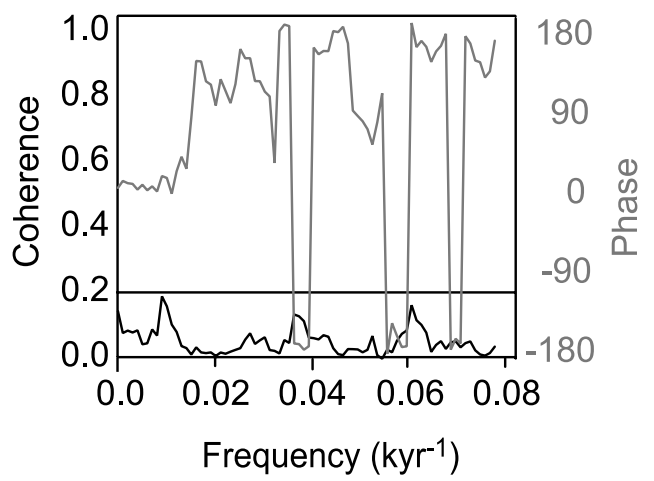

Figure 13. (a) Coherence between pARM-normalized paleointensity and the $\mathrm{S}$ ratio for the entire composite record. The horizontal black line represents the 95\% confidence level. (b) Same as Figure 13a but for the long normal, C5n.2n, only. Note that the very small peak in coherence at $\sim 0.005 \mathrm{kyr}^{-1}$ is not present above the $95 \%$ confidence level in Figure 13b. Together, the plots suggest that changes in magnetic mineralogy have no effect the paleointensity analysis. 


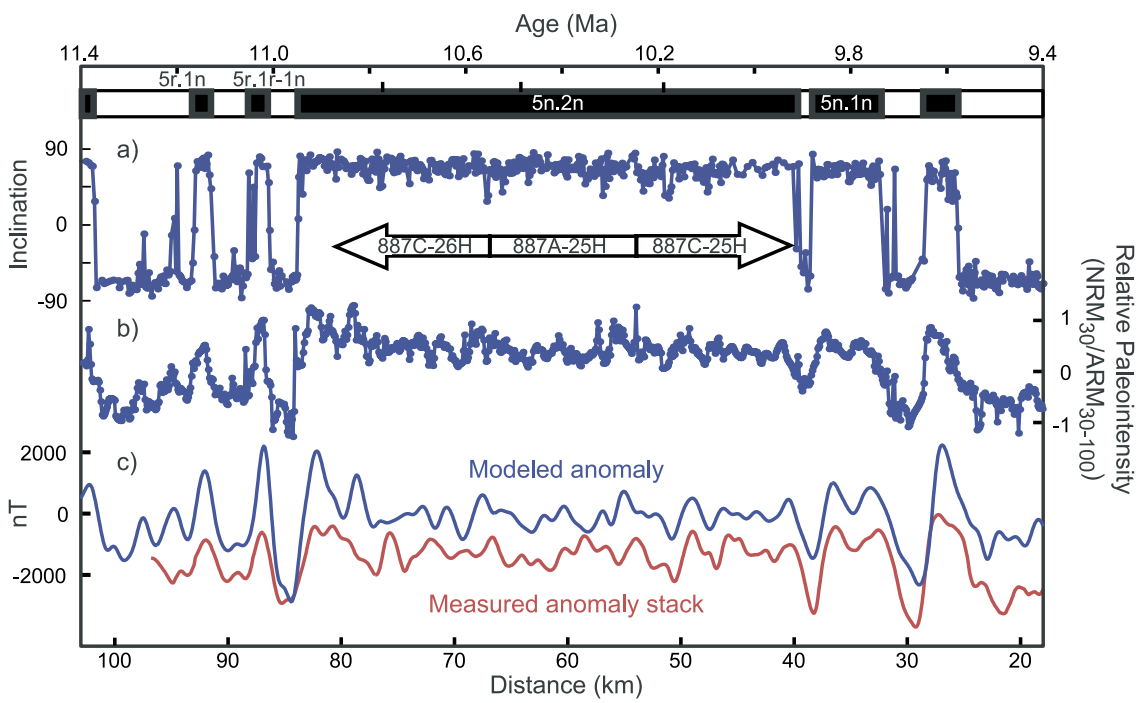

Figure 14. (a) Inclination and (b) relative paleointensity determined from sediments. Relative paleointensity shown as $\mathrm{NRM}_{30} / \mathrm{pARM}_{30-100}$ multiplied by sign of inclination. (c) Forward model from sedimentary data (blue) and measured marine magnetic anomaly stack (red) from the north Pacific. Measured anomaly stack is offset from the zero line for better comparison of the two records. Timescale shown is that of Cande and Kent [1995], with Chron 5n.2r separated into two normal polarity events as in Bowers et al. [2001]. Tick marks on top of timescale correspond to proposed cryptochrons [Cande and Kent, 1992].

random changes in the SAR during the interval $\mathrm{C} 5 \mathrm{n} .2 \mathrm{n}$ in the following manner. (See McMillan et al. [2002], for further details.)

[32] We assume the ages of the interval end points are known exactly and specify two parameters. The first, $L$, gives the length-scale over which the SAR varies. This is a discrete model in which a random jump in SAR occurs every $L \mathrm{~m}$ downcore. The second, $a$, controls the probable size of the jumps. There is no evidence that variations during the Holocene were larger than $50-100 \%$ of the mean rate, and we choose $a$ so that each jump has very little chance of being more than $100 \%$ of the mean rate. A sequence of identically distributed, uniform random variables is generated, summed and scaled to units of age. This sum is transformed in such a way that the beginning and end are constrained to match the ages of the interval end points. In between, the sum is a randomly spaced, monotonically increasing set of ages that correspond to the SAR jump depths, which, by definition, are evenly spaced. The random jumps in SAR at depth increments $L$ are found by dividing $L$ by each of the random time intervals described above. In other words, each depth interval $L$ has associated with it a different age interval, and thus a different SAR. The result is a piecewise-constant, randomly varying SAR as a function of age. If we assume a constant SAR between the interval end points, the age sequence is evenly spaced and no jumps occur. The constant rate relates the specified length-scale of the jumps to an approximate timescale through $L /$ constant SAR). The measurements of relative intensity have been taken at a different set of discrete depths. The perturbed ages of the measurements are found by integration of the reciprocal piecewise-constant SAR with respect to depth from the top of the interval down to the measurement depth.

[33] We then use this new perturbed record as magnetization input to the crustal forward model. This modeled anomaly is compared to the original modeled anomaly to evaluate how much coherence we lose from changes in SAR alone. Results of this exercise (Figure 17) show that for $L=5 \mathrm{~cm}$, corresponding to a SAR jump every $5 \mathrm{kyr}$ on average, a fall off in coherence occurs at frequencies of $\sim 0.03-0.035 \mathrm{kyr}^{-1}(\sim 28-33 \mathrm{kyr})$. A timescale of $10 \mathrm{kyr}(L=10 \mathrm{~cm})$ results in an even more dramatic fall off in coherence, approaching 
a)

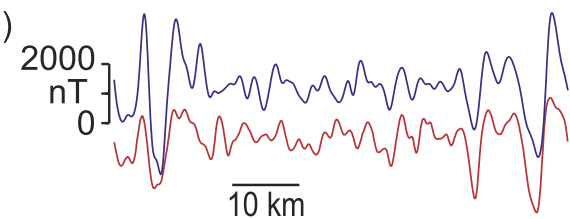

b)

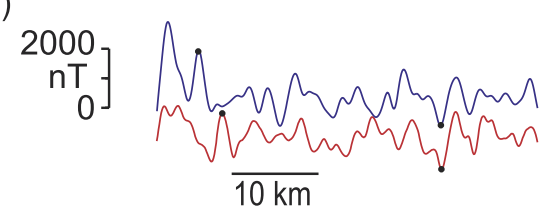

c)

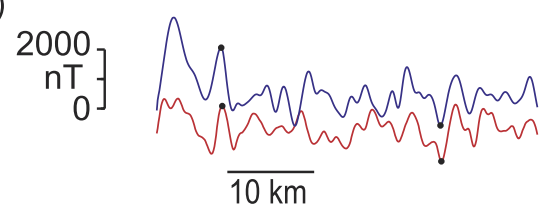

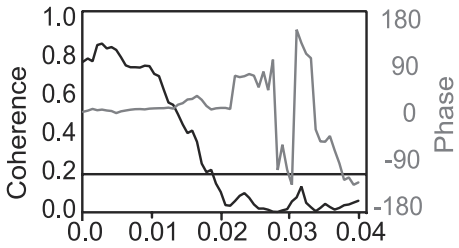
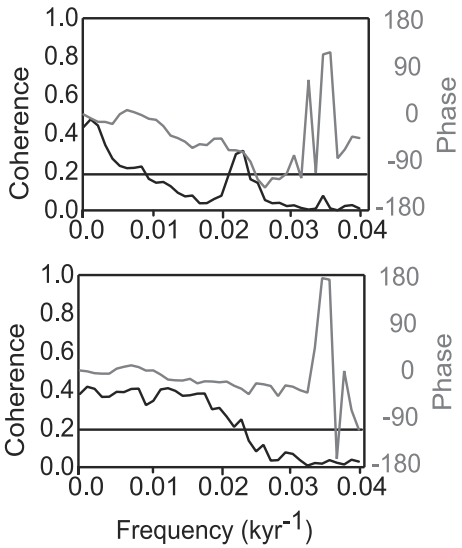

Figure 15. (a) Coherence between forward model (blue/top) and deep-tow stack (red/bottom). (b) Same as above but including only Chron C5n.2n (i.e., excluding all known reversals). (c) Same as Figure 15b, but adding two tie points within Chron C5n.2n, as shown by black dots. Black horizontal line in coherence plots indicates $95 \%$ confidence that the two lines are correlated.

levels that we see in the actual sediment/deep-tow comparison. The increase in coherence at high frequencies (Figure 17) is an artifact of the Earth filter [Blakely, 1995], which substantially attenuates high frequencies. This phenomenon has been previously observed by Parker [1997], who demonstrated that a lineated source with white noise magnetization observed along two parallel tracks has high coherence.

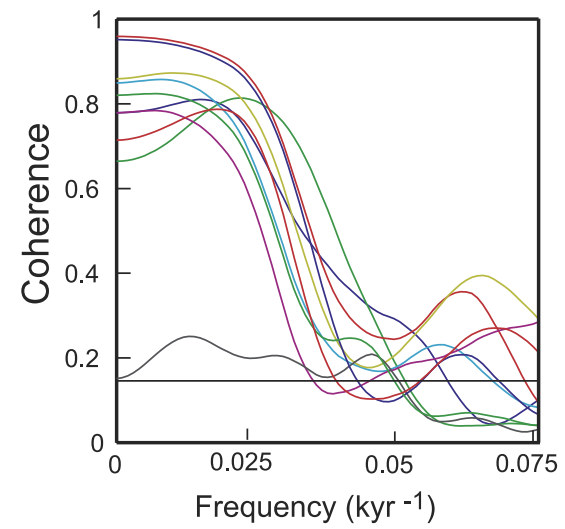

[34] In addition to loss of coherence due to stacking and SAR changes, we can expect further decreases to result from spreading rate variations, ridge jumps, and uncertainties in relative paleointensity data. In light of these factors and considering that we are comparing records with completely different recording mechanisms that are $\sim 1800 \mathrm{~km}$ apart, the observed coherence can be taken as a minimum bound on agreement between the two

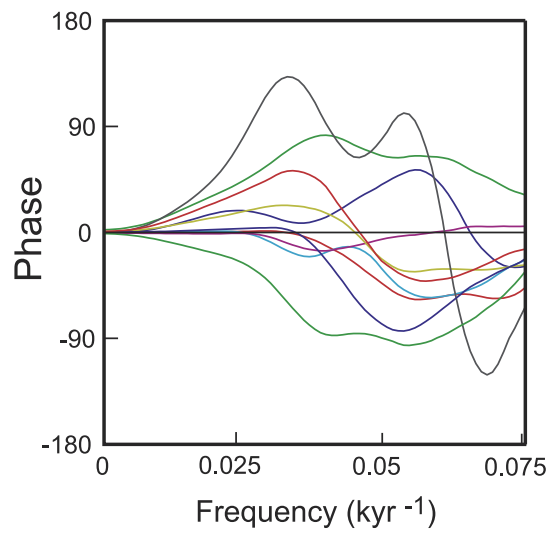

Figure 16. Coherence between the original 4-line anomaly stack and a re-stacking of the lines after imposing random errors $(1 \sigma=10 \mathrm{kyr})$ in choosing the tie points (see text). The different lines represent 10 different realizations of this process. Horizontal black line on the coherence plot is the $95 \%$ confidence level. Note the significant lack of coherence at frequencies greater than $\sim .04 \mathrm{kyr}-1$ (periods less than about $25 \mathrm{kyr}$ ). 
a)

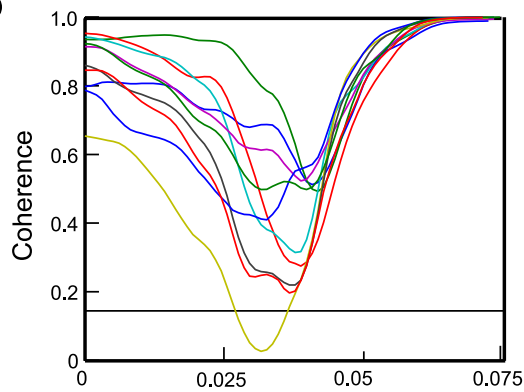

b)

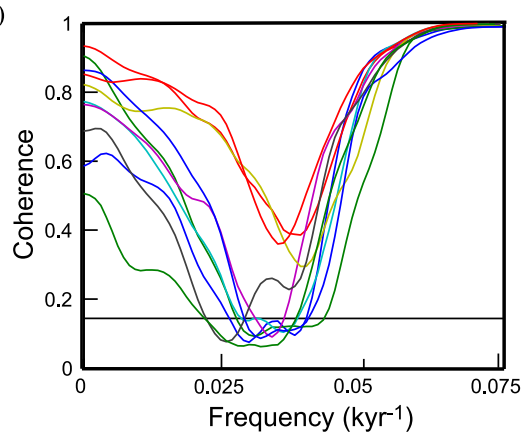

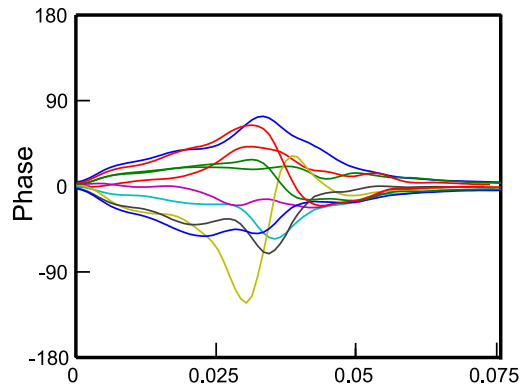

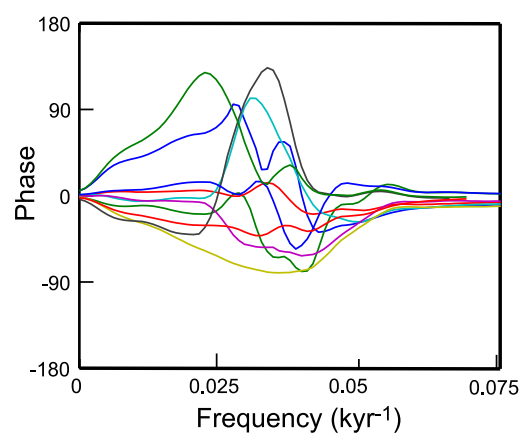

Figure 17. Coherence and phase between the original modeled anomaly representing the "true" field variations, and a model produced from an imaginary sedimentary column which recorded these field variations perfectly, but with random changes in sediment accumulation rate (see text). (a) Random jumps in SAR occur with a time constant of $5 \mathrm{kyr}$. (b) Time constant of $10 \mathrm{kyr}$. The different lines correspond to 10 different realizations of this process. Black horizontal line is the $95 \%$ confidence level. The increase in coherence at high frequencies is an artifact resulting from a white noise source in the crust (see text).

records. We further point out that a forward model using the SIRM-normalized paleointensity shows significant coherence over Anomaly 5n.2n only (without the additional tie points) to $\sim 66 \mathrm{kyr}$, rather than the $100 \mathrm{kyr}$ in the pARM-normalized model. This is further evidence that much of the character of the tiny wiggles in the deep-tow data can be accounted for with variations in paleointensity alone.

\subsection{Temporal Resolution}

[35] It is important to point out that while our original sample spacing was intended to be at least every $2.5 \mathrm{~cm}$, corresponding to $2.5 \mathrm{kyr}$ (on average), actual sample spacing is sometimes greater than that. Because of sampling problems detailed above, as well as short intervals containing ash and samples used for thermal demagnetization, occasional gaps of up to $20 \mathrm{~cm}$ occur in the composite record. However, during the long normal C $5 n .2 n$, the largest gap is $11.5 \mathrm{~cm}$, and $81 \%$ of this part of the record has sample spacing of $\leq 5 \mathrm{~cm}$, while
$70 \%$ is sampled at $2.5 \mathrm{~cm}$ spacing. With a maximum gap of $11.5 \mathrm{~cm}(\sim 11.5 \mathrm{kyr})$, the field would have to reverse twice within exactly that interval for us to miss it. It therefore seems unlikely that if several short reverse polarity intervals exist, they all fall entirely within our sampling gaps. Therefore if reverse intervals do exist within Chron C5n.2n, they are likely $<5 \mathrm{kyr}$ in duration.

[36] As discussed above, other studies have documented short reverse intervals within C 5 n. 2 n. It could be suggested that our slow sedimentation rate would not provide us with sufficient temporal resolution to identify these intervals. While several of the earlier studies have higher sedimentation rates, all have a significantly coarser temporal sampling of C5n.2n than our study. With $3701-\mathrm{cm}$ samples within C5n.2n, our temporal resolution should be far higher than any previous study, with the exception of Rösler and Appel [1998]. The next most densely sampled study has only $\sim 806.6-\mathrm{cm}^{3}$ samples within C $5 \mathrm{n} .2 \mathrm{n}$ [Roberts and Lewin-Harris, 2000]. 
[37] If sample density does not prevent us from identifying reverse intervals seen by others, another concern might be the potential smoothing effects of post-depositional remanence (pDRM) and bioturbation on slow-sedimentation data. However, no reliable evidence exists for significant pDRM smoothing in deep-sea sediments [see, e.g., Katari et al., 2000; Tauxe et al., 1996; Hartl and Tauxe, 1996]. Furthermore, recent work by Katari et al. [2000] shows that remagnetization of bioturbated sediments only occurs when sediments are resuspended at the sediment-water interface as fecal pellets. Below the interface, bioturbation does not result in a change of magnetization. Because the bioturbated layer is completely reworked and resuspended several times a year-a timescale much faster than that of changes in the magnetic field - bioturbation only results in a lock-in delay with respect to deposition, not a smoothing of the record. Comparison of deep-sea sediment records with sedimentation rates varying from $1-11 \mathrm{~cm} /$ kyr [Hartl and Tauxe, 1996] provides further evidence that smoothing of the geomagnetic signal is insignificant in slow-sedimentation data. Hartl and Tauxe [1996] observe no smoothing of relative paleointensity data over the Brunhes-Matayama transition in even the most slowly accumulated record.

[38] We suggest therefore that the temporal resolution of our core is not a factor obscuring reverse intervals seen by others. Instead, we propose the possibility that many of the other studies are marred by large scatter of non-geomagnetic origin (e.g., drilling-related disturbances or other deformation). However, the interval observed in both Siwaliks records [Tauxe and Opdyke, 1982; Rösler and Appel, 1998], and the interval in both Icelandic volcanic records [Watkins and Walker, 1977; McDougall et al., 1984], suggests that at least one of these short intervals may be real, and not an artifact of local deformation. The absence of such a reverse interval in our densely sampled record from Site 887, as well as many other sedimentary records, suggests another possibility: that at least some of the short intervals seen by others result from non-dipole fluctuations and thus may not be observed globally.
[39] There is some evidence that these apparent reversals or directional anomalies are associated with intensity lows [e.g., Kent and Schneider, 1995; Tauxe and Hartl, 1997; Langereis, 1999]. If the low dipole intensity results in a relatively strong non-dipole field, such geographically varying directional anomalies are to be expected. Additional high-resolution studies in non-disturbed sediments around the world would be helpful in further clarifying the issue.

\section{Conclusions}

[40] While it is nearly impossible to prove that short reverse polarity intervals do not exist within Chron C5, this study makes a convincing case that such events do not occur in the North Pacific and are unlikely to be global in nature. Instead, the short-wavelength anomaly variations in Chron C5 are more likely produced by paleointensity variations. Our major conclusions are as follows:

[41] 1. The sediments from ODP Site 887 are suitable for relative paleointensity analysis, and the directional scatter observed in the data is entirely consistent with geomagnetic secular variation. This suggests that our data are not likely to be affected by drilling-related disturbances or other deformation.

[42] 2. No directional evidence exists in this sediment record for reverse polarity intervals within Chron C5n.2n.

[43] 3. If short reverse polarity intervals do exist at this site, their likely duration must be $<5 \mathrm{kyr}$, although a few sampling gaps allow at least the possibility of longer intervals.

[44] 4. The globally coherent tiny wiggles in Anomaly 5 can be reproduced quite well with actual relative paleointensity variations recorded by sediments at Site 887 .

[45] 5. Because in some instances multiple records from a single geographical region appear to confirm the existence of the same negative polarity event, we suggest that these events within Chron C5n.2n are not global in nature and thus do not result from reversals of the dipole field. 


\section{Acknowledgments}

[46] The authors are very grateful to Tom Werth for the huge amount of work involved in sampling the cores and performing most of the laboratory work. Thanks also to Jason Steindorf, Winter Miller, and Andrew Harris for helping with the measurements. Reviewers Luca Lanci and Toshi Yamazaki provided very helpful comments on the manuscript. This work was supported by NSF grant OCE0099294 to L. Tauxe.

\section{References}

Blakely, R. J., Geomagnetic reversals and crustal spreading rates during the Miocene, J. Geophys. Res., 79, 29792985, 1974.

Blakely, R. J., Potential Theory in Gravity and Magnetic Applications, 441 pp., Cambridge Univ. Press, New York, 1995.

Bleil, U., Magnetostratigraphy of Neogene and Quaternary sediment series from the Norwegian Sea: Ocean Drilling Program Leg 104, Proc. Ocean Drill. Program Sci. Results, 104, 829-840, 1989.

Bowers, N. E., S. C. Cande, J. S. Gee, J. A. Hildebrand, and R. L. Parker, Fluctuations of the paleomagnetic field during chron $\mathrm{C} 5$ as recorded in near-bottom marine magnetic anomaly data, J. Geophys. Res., 106, 26,379-26,396, 2001.

Cande, S. C., and D. V. Kent, A new geomagnetic polarity time scale for the Late Cretaceous and Cenozoic, J. Geophys. Res., 97, 13,917-13,951, 1992.

Cande, S. C., and D. V. Kent, Revised calibration of the geomagnetic polarity timescale for the Late Cretaceous and Cenozoic, J. Geophys. Res., 100, 6093-6095, 1995.

Cande, S. C., and J. L. LaBrecque, Behavior of the Earth's palaeomagnetic field from small scale marine magnetic anomalies, Nature, 247, 26-28, 1974.

Chamalaun, F. H., and I. McDougall, Dating geomagnetic polarity epochs in Réunion, Nature, 210, 1212, 1966.

Constable, C. G., L. Tauxe, and R. L. Parker, Analysis of 11 Myr of geomagnetic intensity variation, J. Geophys. Res., 103, 17,735-17,748, 1998.

Cronin, M., L. Tauxe, C. Constable, P. Selkin, and T. Pick, Noise in the quiet zone, Earth Planet. Sci. Lett., 190, 13-30, 2001.

Fisher, R. A., Dispersion on a sphere, Proc. R. Soc. London, Ser. A, 217, 295-305, 1953.

Garcés, M., J. Agustí, L. Cabrera, and J. M. Parés, Magnetostratigraphy of the Vallesian (late Miocene) in the Vallès-Penedès Basin (northeast Spain), Earth Planet. Sci. Lett., 142, 381-396, 1996.

Gradstein, F. M., F. P. Agterberg, J. G. Ogg, J. Hardenbol, P. van Veen, J. Thierry, and Z. Huang, A Mesozoic timescale, J. Geophys. Res., 99, 24,051-24,074, 1994.

Hartl, P., and L. Tauxe, A precursor to the Matuyama/Brunhes transition field instability as recorded in pelagic sediments, Earth Planet. Sci. Lett., 138, 121-135, 1996.

Katari, K., L. Tauxe, and J. King, A reassessment of postdepositional remanent magnetism: preliminary experiments with natural sediments, Earth Planet. Sci. Lett., 183, 147160, 2000.

Kent, D. V., and D. A. Schneider, Correlation of paleointensity variation records in the Brunhes/Matuyama polarity transition interval, Earth. Planet. Sci. Lett., 129, 135-144, 1995.

King, J. W., S. K. Banerjee, and J. Marvin, A New rockmagnetic approach to selecting sediments for geomagnetic paleointensity studies: Application to paleointensity for the last 4000 years, J. Geophys. Res., 88, 5911-5921, 1983.

Kok, Y. S., and L. Tauxe, Long-tau VRM and relative paleointensity estimates in sediments, Earth Planet. Sci. Lett., 168, 145-158, 1999.

LaBrecque, J. L., D. V. Kent, and S. C. Cande, Revised magnetic polarity time scale for Late Cretaceous and Cenozoic time, Geology, 5, 330-335, 1977.

Langereis, C. G., Excursions in geomagnetism, Nature, 399, 207-208, 1999.

Li, J.-J., et al., Late Cenozoic magnetostratigraphy (11-0 Ma) of the Dongshanding and Wangjiashan sections in the Longzhong Basin, western China, Geologie en Mijnbouw, 76, 121-134, 1997.

Lowrie, W., Identification of ferromagnetic minerals in a rock by coercivity and unblocking temperature properties, Geophys. Res. Lett., 17, 159-162, 1990.

Mankinen, E. A., and C. S. Gromme, Paleomagnetic data from the Coso Range, California and current status of the Cobb Mountain normal geomagnetic polarity event, Geophys. Res. Lett., 9, 1279-1282, 1982.

Mankinen, E. A., J. M. Donnelly, and C. S. Gromme, Geomagnetic polarity event recorded at $1.1 \mathrm{~m}$. y. B. P. on Cobb Mountain, Clear Lake volcanic field, California, Geology, 6, 653-656, 1978.

McDougall, I., and N. D. Watkins, Age and duration of the Réunion geomagnetic polarity event, Earth Planet. Sci. Lett., 19, 443-452, 1973.

McDougall, I., L. Kristjansson, and K. Saemundsson, Magnetostratigraphy and geochronology of Northwest Iceland, J. Geophys. Res., 89, 7029-7060, 1984.

McFadden, P. L., R. T. Merrill, M. W. McElhinny, and S. Lee, Reversals of the Earth's magnetic field and temporal variations of the dynamo families, J. Geophys. Res., 96, $3923-$ 3933, 1991.

McMillan, D. G., C. G. Constable, and R. L. Parker, Limitations on stratigraphic analyses due to incomplete age control and their relevance to sedimentary paleomagnetism, Earth Planet. Sci. Lett., 201, 509-523, 2002.

Merill, R. T., M. W. McElhinny, and P. L. McFadden, The Magnetic Field of the Earth, 527 pp., Academic, San, Diego, Calif., 1998.

Opdyke, N. D., J. E. T. Channell, Magnetic Stratigraphy, 346 pp., Academic, San Diego, Calif., 1996.

Parker, R. L., and S. P. Huestis, The inversion of magnetic anomalies in the presence of topography, J. Geophys. Res., 79, 1587-1593, 1974.

Parker, R. L., Coherence of signals from magnetometers on parallel paths, J. Geophys. Res., 102, 5111-5117, 1997. 
Rea, D. K., I. A. Basov, T. R. Janecek, A. Plmer-Julson, and Shipboard Scientific Party, Proceedings of the Ocean Drilling Program Initial Report, vol. 145, Ocean Drill. Progran, College Station, Tex., 1993.

Roberts, A. P., and J. C. Lewin-Harris, Marine magnetic anomalies: evidence that "tiny wiggles" represent short-period geomagnetic polarity intervals, Earth Planet. Sci. Lett., 183, 375-388, 2000.

Roperch, P., G. Hérail, and M. Fornari, Magnetostratigraphy of the Miocene Corque basin, Bolivia: Implications for the geodynamic evolution of the Altiplano during the late Tertiary, J. Geophys. Res., 104, 20,415-20,429, 1999.

Rösler, W., and E. Appel, Fidelity and time resolution of the magnetostratigraphic record in Siwalic sediments: high-resolution study of a complete polarity transition and evidence for cryptochrons in a Miocene fluviatile section, Geophys. J. Int., 135, 861-875, 1998.

Schneider, D. A., Paleomagnetism of some Leg 138 sediments: Detailing Miocene magnetostratigraphy, Proc. Ocean Drill. Program Sci. Results, 138, 59-72, 1995.

Schouten, H., and McCamy, Filtering marine magnetic anomalies, J. Geophys. Res., 77, 7089-7099, 1972.

Tanaka, H., M. Kono, and H. Uchimura, Some global features of paleointensity in geological time, Geophys. J. Int., 120, 97-102, 1995.

Tauxe, L., Sedimentary records of relative paleointensity of the geomagnetic field: Theory and practice, Rev. Geophys., 31, 319-354, 1993.
Tauxe, L., and P. Hartl, 11 million years of Oligocene geomagnetic field behavior, Geophys. J. Int., 128, 217-229, 1997.

Tauxe, L., and N. D. Opdyke, A Time framework based on magnetostratigraphy for the Siwalik sediments of the Khaur area, Northern Pakistan, Palaeogeogr. Palaeoclimatol. Palaeoecol., 37, 43-61, 1982.

Tauxe, L., P. Tucker, N. P. Peterson, and J. L. LaBrecque, Magnetostratigraphy of leg 73 sediments, Proc. Ocean Drill. Program Sci. Results, 73, 609-621, 1984.

Tauxe, L., T. Pick, and Y. S. Kok, Relative paleointensity in sediments: A pseudo-Thellier approach, Geophys. Res. Lett., 22, 2885-2888, 1995.

Tauxe, L., T. Herbert, N. J. Shackleton, and Y. S. Kok, Astronomical calibration of the matuyama-Brunhes boundary: Consequences for magnetic remanence acquisition in marine carbonates and the Asian loess sequences, Earth Planet Sci. Lett., 140, 133-146, 1996.

Thellier, E., and O. Thellier, Sur l'intensité du champ magnétique terrestre dans le passé historique et géologique, Ann. Geophys., 15, 285-378, 1959.

Thompson, R., and F. Oldfield, Environmental Magnetism, 227 pp., Allen and Unwin, Concord, Mass., 1986.

Watkins, N. D., and G. P. L. Walker, Magnetostratigraphy of Eastern Iceland, Am. J. Sci., 277, 513-584, 1977.

Weeks, R. J., A. P. Roberts, K. L. Verosub, M. Okada, and G. J. Dubuisson, Magnetostratigraphy of upper Cenozoic sediments from leg 145, North Pacific Ocean, Proc. Ocean Drill. Program Sci. Results, 145, 491-521, 1995. 